Review

\title{
Deep Eutectic Solvents Feasibility in Oil and Gas Processing Field for Contaminated $\mathrm{CO}_{2}$ Control
}

\author{
Ihtisham Ul Haq 1,2, Bhajan Lal 1,2 and Dzulkarnain Zaini 1,2 \\ 1 Ihtisham_20000019@utp.edu.my \\ 2 bhajan.lal@utp.edu.my \\ ${ }^{1}$ Department of Chemical Engineering, Universiti Teknologi PETRONAS, 32610, Seri Iskandar, \\ Perak, Malaysia. \\ ${ }^{2} \mathrm{CO}_{2}$ Research Centre (CO2RES), Universiti Teknologi PETRONAS, Bandar Seri Iskandar, 32610, \\ Perak, Malaysia \\ ${ }^{3}$ Centre for Advance Process Safety (CAPS), Universiti Teknologi PETRONAS, 32610 Seri Iskandar, \\ Perak, Malaysia \\ Correspondence: bhajan.lal@utp.edu.my
}

\begin{abstract}
Carbon dioxide capture and storage (CCS) is highly expected to be mitigating the discharges of carbon dioxide in a surrounding environment. Solvents are an integral part of CCS. So far, several solvents have been explored the interest of meeting the requirements such as accessibility, non-harmfulness, biocompatibility, recyclability, and inexpensiveness. However, most solvents face failure in fulfilling the requirements due to many factors, so, this review paper gives a brief discussion about another category of solvent, an analogue of ionic liquids (ILs) named deep eutectic solvent (DES). Extensive research has been done on DES in recent years because of their various attractive advantages, i.e., non-poisonousness, biodegradability, cheap cost and easy preparation, that make them as a promising green solvent for many industrial procedure and application, for instance, polymer synthesis, biodiesel treatment, green chemistry, electrochemistry etc. Therefore, this manuscript mainly focusses on $\mathrm{CO}_{2}$ capturing through DES in oil and gas field. In addition, the preparation and chemical structures of this novel solvent (DES) is also discussed. Moreover, a detailed study based on experimental solubility of $\mathrm{CO}_{2}$ in DESs is also reported in this article.
\end{abstract}

Keywords: Carbon dioxide capture; Deep eutectic solvents; Ionic liquids.

\section{Introduction}

As the requirements of modern civilisation have been increasing rapidly, the industries continuously produce to meet the demands. As a result, a large amount of $\mathrm{CO}_{2}$ is released from industries, for example, the production of cement and lime, sugar from sugarcane, 
and the combustion of coal, and natural gas. Every year 3 billion tonne $\mathrm{CO}_{2}$ is added to the atmosphere. Nevertheless, the releasing of coal gas from the production process is one of the utmost greenhouse gas emission, which plays an important role in global warming resulting in urban smog, acid rain and bad impact on human life [1]-[2]. In the preceding decade, $\mathrm{CO}_{2}$ capture and storage (CCS) from oil \& gas has been assumed as one of the pertinent methodologies. The use of alkanolamine in the absorption process of $\mathrm{CO}_{2}$ is investigated by several researchers. The cost-effective methods of $\mathrm{CO}_{2}$ capturing by utilising new absorbents provide a possible solution to overcome the greenhouse effect up to some extent. DES is a feasible solvent in green chemistry, that has an optimistic approach in the oil and gas field when comparing with the currently avaiable conventional solvents.Augmentation of $\mathrm{CO}_{2}$ concentration in the atmosphere because of human exercises is accepted to be one of the fundamental reasons, which can cause an unnatural climate change [3]. On account of its unfavourable impact on the surrounding environment, rural life and also fiscal implications of climate crisis or climate warms, resources have been expended to diminish the emanations of harmful gases such as tetrafluoromethane and other ozone-depleting substance along with $\mathrm{CO}_{2}$ [4-5]. It has been observed during the last decade that the environmental $\mathrm{CO}_{2}$ concentration extended from 350-403 ppm; which indicates the impermissible increment in comparison to the previous 20 decades[3-6]. There are four major origins of carbon dioxide discharge. (1) Manufacturing process (2) consumption of fossil energy in heat and electricity plants, (3) the feedstock of hydrocarbon as a source of hydrogen gas manufacturing (4) exudation of $\mathrm{CO}_{2}$ from vehicles [5]. Numerous methodologies have been implemented for $\mathrm{CO}_{2}$ capture from the sources of producing electricity from fossil energy. To name a few, membrane, adsorption, physiochemical absorption and cryogenic are some of the highly implemented procedures for $\mathrm{CO}_{2}$ capture [7]. The absorption process is observed as the most encouraging technology; it is beneficial as compared to adsorption, cryogenic and membrane processes regarding cost and $\mathrm{CO}_{2}$ catching performance [7-8]. Recently, alkanolamines have caught the attention and mostly used for $\mathrm{CO}_{2}$ capture [9]-[11]. However, drawbacks have appeared by using Alkanolamines industrially, such as being harmful, inflammable, un-green and causing corrosion [12]-15]. ILs have been paid special consideration as a substitution to a conventional method, due to their ability to tune their physicochemical properties and hence their liking for $\mathrm{CO}_{2}$ molecules by choosing the appropriate ions [16], [17]. Though ILs have also revealed a few drawbacks concerning their application for carbon capture purposes, for example, their high viscosity or their cost, which have thwarted their use for capturing purposes at the industrial scale [18-19]. However, these disadvantages are not supposed to be a reason to stop the progress towards attainable $\mathrm{CO}_{2}$ capture. Many alternatives have been suggested to sustain the design of ILs while keeping away their notable problems. Moving toward green solvents technology, DESs were presented for many applications. Mainly, DESs have been recognised as a viable solvent in comparing with conventional solvent in term of physiochemical properties such as environmentally friendly, high biocompatibility, inexpensive, easy to synthesis, low volatility [20-21]. In this sense many researchers have been stressed on the extensive variety of applications of DES in various field, such as for instance biodiesel synthesis, synthesis of polymers related materials, and different branch of chemistry especially, 
electrochemistry, analytical chemistry, physical chemistry and $\mathrm{CO}_{2}$ capturing technology [22-26]. There are enormous articles have been published on DESs contribution in the given fields since 2003. The goal of this review is to exhibit the possible and beneficial usage of DESs for contaminated $\mathrm{CO}_{2}$ capturing in petroleum and gas industry and also the investigations of DESs regarding their physical properties, chemical properties, applications, chemical structure, preparation and lastly experimental solubilities $\mathrm{CO}_{2}$ were accounted and compared in this work, which showed DESs feasibility over conventional solvents. It is hoped that in future, DES will show better performance in oil and gas fields.

\section{Deep eutecticsolvents}

The expanding requests for environmentally friendly procedures inside the system of green chemistry and acknowledgment of phenomenal and favourable features of DESs have led, in the previous twenty years, to a developing enthusiasm for utilisation of these blends as substitutes to conventional organic solvents and their procedure ionic liquids (IL) in various fields. Based upon green chemistry, deep eutectic solvent may be assumed as an adaptable substitute to ILs because of their excellent properties, for instance, non-volatility, reliability, cheap cost and high biocompatibility [20-27]. DESs are usually prepared by mixing of two or three cheap components, that may have the ability to make hydrogen interactions to form a eutectic mixture, because of interaction, the melting point lower than that of every individual component. DES is supposed to be an aqueous state at a temperature lower than $100^{\circ} \mathrm{C}$ [27]. The concept of deep eutectic solvents was first elucidated by Abbot et al. [28]. Based on mixing of choline chloride (HBA) and urea (HBD) with 1:2 molar ratio and the melting point was $12^{\circ} \mathrm{C}$ [28] ILs vary from DESs in three major perspectives, firstly, ionic liquids are costly, and some of them exhibit high poisonousness, just as having poor biodegradability, feasibility. On the other hand, DES are inexpensive, biocompatible and environmentally friendly. Another embodiment is the preparations procedures of ILs. Also, DESs are varied somewhat, the preparations of DESs are achieved by blending of two or more constituent, which produce no waste and not needed to be purified, while ILs are tough and costly as well. Lastly, ILs are comprised totally of ions, which interact by ionic bonds; however, DESs contain both ionic and neutral species [29]. Having set themselves up over the most recent few decades, as helpful and regarded as a substitute to fluid and traditional solvents, the potential applications of DES have been broadly investigated. For instance, Xiang et al. (2015) have utilised choline chloride and urea-based DES system for $\mathrm{Fe}_{2} \mathrm{O}$ nano spindles [30]. Gu et al. examined the utilization of DESs choline chloride $(\mathrm{ChCl})$ and glycerol $(\mathrm{GL})$ in the transesterification of oilseed rape to generate biodiesel [31]. Likewise, Hayyan et al. used ChCl-based DESs as an additive for producing biodiesel from acidic crude palm oil [32]. Also, the proficiency of deep eutectic solvents in $\mathrm{CO}_{2}$ Capture technology has been explored. Not long ago, García et al. revealed a density functional theory simulations report on moderation of $\mathrm{CO} 2$ through modern DESs at the molecular level [21]. Moreover, the vast number of experiments and hypothesis were done in the applications of DESs in $\mathrm{CO}_{2}$ capturing technology [33-34]. The physiochemical characteristics of DESs were investigated by various researchers all around the world, because of, their favourable applications are good industrially [20-27]. Sirat et al. elucidated the physical entities of manganese (II) use as the basis DESs [35]. Furthermore, 
another researcher explored the physical features of triglycol as (HBD) with the five mixture of phosphonium and ammonium salts as (HBD) based DESs [20]. On the other hand, many researchers have investigated the toxicity of deep eutectic solvent, and it was discovered that DESs are ordinary, not harmful. Hayyan et al. recently examined the toxicity of choline chloride (HBD) based DESs with four hydrogen donors (HBD), namely, glycerin, ethylene glycol, tri ethylene glycol and urea, the tested DESs revealed as innocuous [36]. Additionally, Huang et al. figured out the harmfulness test on Hydra Sinensis. $\mathrm{ChCl}$ and urea-based DESs, it exhibited that DESs could be less damaging as compared to each component [37]. DESs are getting a viable option for both ionic liquid and conventional solvents. It depends upon many factors, but the most significant is the physicochemical properties.

\section{Preparation and chemical structure of DES}

In general, the chemical structure of solvents is very essential in deciding their interaction to various solutes. However, when it comes to DESs, minimal investigations have been on the microscopic agents which may influence the structure and characteristics of the DES. In other words, the connection and intermolecular interaction of hydrogen bond donor and hydrogen bond accepter which have a critical effect on the properties have not been explored [21]. At the beginning period, with respect to this research, there were less accessible research papers in the literature examining the intermolecular structure of the constituents of hydrogen bond donors ( $\mathrm{HBD}_{\mathrm{s}}$ ) and hydrogen bond acceptors (HBAs). Very recently, Aissaoui et al. determined the properties of various glycols such as diglycol and triglycol by the help of COSMO-RS [38]. The study indicated the further possibility of hydrogen bonding that occurred during the formulation of new solvent. Furthermore, Abbot et al. and Perkins et al. have explained the interactions of DESs [28-39]. In another study, Zang et al. examined choline chloride and magnesium chloride hexahydrate based DESs, by applying DFT method to explore the stable key structure of molecules in DES. On the hand, the right design of DES and to reasonably grow their application, the complete comprehension of the physical properties is important.

The preparation of DES is simple by the mixing of hydrogen bond donor (HBD) and hydrogen bond acceptor (HBD) at a specific temperature in of two ways, (1) when the HBD and HBA are mixed, the lower melting point constituent begins to melt and then the remaining compound which has a high melting point is put into the liquid and the mixtures are melted collectively, and (2) when both constituents are mixed and melt together, since the first work of Abbot et al. 2003 [28]. For example, the solid beginning material of $\mathrm{ChCl}$ and Urea were heated at 1:2 proportional to acquire a blend that was liquid at ambient temperature, numerous DES prepared, as studied in [40-41]. Figure 1 represents components in DES and how it interacts or make the bond with one another during the formation of DES molecule. Moreover, it is found that humidity can significantly impact on the properties of DES. Hence, it is profoundly imperative to keep $\mathrm{HBA}_{\mathrm{s}}, \mathrm{HBD}_{\mathrm{s}}$, and the prepared DES away from the vapour or steams. It is supposed to be noticed that the homogeneous mixture of liquid is the ending stage of the procedure of Deep eutectic solvent preparation. 


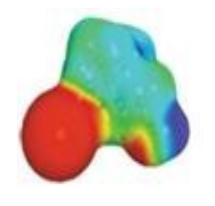

$\mathrm{ChCl}$

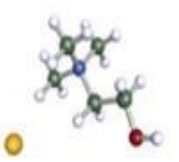

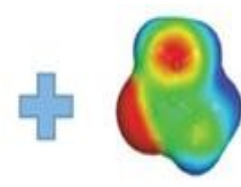

Urea

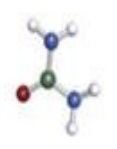

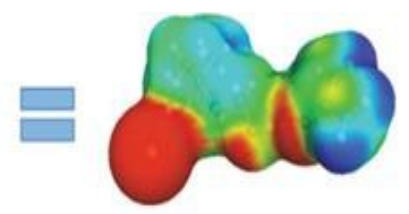

DES
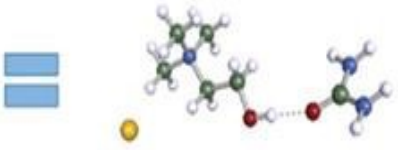

FIGURE 1. Chemical structure of Reline Constituted type III DES [42].

Abbot et al. divided DES into three various groups through its general equation as shown in Table (1) [43].

Table 1. This is a table that represents various classes

\begin{tabular}{c|c}
\hline Class I : quaternary ammonium salt + metal chloride & $(\mathrm{Y}=\mathrm{MClx}, \mathrm{M}=\mathrm{Zn}, \mathrm{Sn}, \mathrm{Fe}, \mathrm{Al}, \mathrm{Ga})$ \\
\hline class II : quaternary ammonium salt + metal chloride hydrate & $\mathrm{Y}=\mathrm{MClx} \cdot \mathrm{yH} 2 \mathrm{O}, \mathrm{M}=\mathrm{Cr}, \mathrm{Co}, \mathrm{Cu}, \mathrm{Ni}, \mathrm{Fe}$ \\
\hline class III : quaternary ammonium salt + hydrogen bond donor & $\mathrm{Y}=\mathrm{R} 5 \mathrm{Z}$ with $\mathrm{Z}=-\mathrm{CONH} 2,-\mathrm{COOH}$, \\
& $-\mathrm{OH}$ \\
\hline class IV : metal chloride hydrate + hydrogen bond donor & \\
\hline
\end{tabular}

Later, class IV DES also described which comprised inorganic chloride, for instance, Iron (II) Chloride blended with glycols and acetamide group $\mathrm{HBD}_{s}[20-44]$.

\section{Potential application of DESs for $\mathrm{CO}_{2}$ capture in oil and gas technology}

The consistent increment of the discharging of carbon dioxide from the combustion of non-renewable energy sources is prognosticated to make huge impact on the worldwide atmosphere [45]. To approach this defiance, the reasonable alternative to manage carbon dioxide releasing is CCS. Usually, there are three ways to deal with $\mathrm{CO}_{2}$ discharge from power plants: (1) to capture $\mathrm{CO}_{2}$ from the releasing sources or burning products, (2) transporting the captured $\mathrm{CO}_{2}$ by vehicles etc. (3) infusing $\mathrm{CO}_{2}$ underground, to improve oil recuperation or saline water or coal mine $[45,46]$. There are different processes through $\mathrm{CO}_{2}$ is captured, but the easiest way which is to be applied as a post-combustion sequester [47]. That incorporates the elimination of pernicious gases like $\mathrm{CO}_{2}$ from exhaust gases [20], that originates from the burning compartment of the generating station [48]. Various other technologies for post-combustion $\mathrm{CO}_{2}$ are used, for example, hydration formation, chemical absorption, membranes, metal frameworks 
[4-5]. The chemical absorption was considered as economical in post-combustion method [49]. The other techniques are reported to be less suitable in post-combustion [7]. Chemical absorption procedure for $\mathrm{CO}_{2}$ used was bottomed on reacting sorbent exothermically with $\mathrm{CO}_{2}$ in the existence of gas flow at ambient temperature [5]. Chemical absorption processes with liquid alkanol amine solution have been used for decades so that the dismissal $\mathrm{CO}_{2}$ from waste gases stream [50]. Though, applying alkanol amines showed drawbacks industrially, for example, formed salt, corrosiveness, high cost, non-biocompatible etc. [51]. Because of these disadvantageous, the researchers started to investigate novel solvents to overcome the existence issues with low cost. Therefore, a new solvent called deep eutectic solvents extensively known as potential substitutes to ILs and conventional solvent [52]. Due its viable characteristics, for instance, accessibility, harmless, non-combustibility, cheap cost, recyclability and biocompatibility [33], DES has been deemed suitable to be applied in CCS technology [24].

\section{Investigational dissolubility of $\mathrm{CO}_{2}$ in DESs}

Even though there are various surveys which have been convened to find out the dissolving power of $\mathrm{CO}_{2}$ in DESs, the $\mathrm{CO}_{2}$ dissolubility in DESs has been reviewed no long ago [53]. For instance, Adeyemi et al. (2017) very recently, investigated the solubility of $\mathrm{CO}_{2}$ in the presence of three amine-based DESs, (ChCl-MEA), (ChCl-DEA) and (ChCl-MDEA. This study described the solubility of nominated DES at the various molar ratio, 1:6, 1:8 and 1:10; it is indicated that the solubility of $\mathrm{CO}_{2}$ increased as the molar ratio of amine in DES increase [54]. Furthermore, Kamgar et al. reported the dissolubility of many various gases, $\mathrm{CO}_{2}, \mathrm{CO}, \mathrm{CH}_{4}, \mathrm{H}_{2}$ and $\mathrm{N}_{2}$ in Choline Chloride/Urea as a DES, by various ratio molar ratios (1:1.5, 1:2.0 and 1:2.5) and temperature extending from $308 \mathrm{~K}$ and $333 \mathrm{~K}$ at pressures up to $5 \mathrm{MPa}$ is resolved. This study indicated the $\mathrm{CO}_{2}$ solubility in the presence of Choline Chloride to Urea based DES [55]. Furthermore, Lu et al. measured $\mathrm{CO}_{2}$ dissolubility in Reline : levulinic acid $\left(\mathrm{C}_{5} \mathrm{H}_{8} \mathrm{O}_{3}\right)$ based DESs, it is revealed selected DESs dissolubility at distinct temperatures, (303.15 up to $333.15 \mathrm{~K}$ ) at $0.6 \mathrm{MPa}$ by fix volume saturation way [56], the result of the selected $\left(\mathrm{C}_{5} \mathrm{H}_{8} \mathrm{O}_{3}\right)$-based upon DESs showed better performance for $\mathrm{CO}_{2}$ capturing as compared to furfuryl alcohol-based upon DES. it is likewise discovered that $\mathrm{CO}_{2}$ dissolution in DESs expended as expending both pressure and molar ratio of levulinic to Choline Chloride or diminished with increasing the temperature. In another study, measured $\mathrm{CO}_{2}$ dissolution in ternary DESs comprising of $\mathrm{ChCl}$ and dihydric alcohols (consisting, butanediol (BD), Butane-2,3-diol, by 1:2 molar ratios of $\mathrm{ChCl}(\mathrm{HBA})$ and dihydric alcohol (HBD) of 1:3 and 1:4 at different temperatures ranging from $293.15 \mathrm{~K}, 303.15 \mathrm{~K}, 313.15 \mathrm{~K}$, and $323.15 \mathrm{~K}$ under 0.6 MPa pressure by way of an isochoric saturation. Henry's constants and thermal behavior or thermodynamics properties, for example, Gibbs free energy, enthalpy and changes in the entropy of $\mathrm{CO}_{2}$ preservation were determined from vitro data. The outcomes from this study demonstrated that the $\mathrm{CO}_{2}$ dissolubility in DESs increment with diminishing temperature and expending pressure, furthermore, DESs consisted of CC and 2,3-butanediol at 1:4 molar ratio exhibited the excellent uptake potential dissolubility of $\mathrm{CO}_{2}$ across all DES s57]. Furthermore, Mirza et al. elucidated $\mathrm{CO}_{2}$ dissolubility's in the presence of three DES s as Reline at 1:2 molar ratio, choline chloride and 
ethane-1,2-diol $\left(\mathrm{CH}_{2} \mathrm{OH}\right)_{2}$ at 1:2 molar ratio and choline chloride, dicarboxylic acid $\left(\mathrm{C}_{4} \mathrm{H}_{6} \mathrm{O}_{5}\right)$, and ethane-1,2-diol $\left(\mathrm{CH}_{2} \mathrm{OH}\right)_{2}$ at1.3:1:2.2 molar ratios at a distinct temperature ranging from 35.85 to $55.85 \mathrm{C}$ and at I.6 Bar pressures. In the same order, in this investigation, Henry's constant, Gibs free energy and both enthalpy and entropy dissolution reveal the $\mathrm{CO}_{2}$ absorption is exothermic as the internal energy decreases, thereby of gas absorption [58]. However, Xie et al. revealed that how water impact on Reline ( $\mathrm{ChCl}$ : urea) with ratio1:2 at operational temperature dimension ranging from $35.05 \mathrm{C}, 45.05 \mathrm{C}$ and $55.05 \mathrm{C}$, and pressure from 6 bar to $45 \mathrm{Bar}$. It has proven the influence of moisture content on DES. Result indicates that the solubility of $\mathrm{CO}_{2}$ decreases as the water vapour increase, yet, water vapor can also effect on viscosity of the selected species [59]. On the other hand, carbon dioxide $\left(\mathrm{CO}_{2}\right)$ separation is assumed significantly as an energy-saving and $\mathrm{CO} 2$ emission reduction.

In recent years, Francisco et al. formed a new DES based on solvents from lactic acid (HBD), $\mathrm{ChCl}$ (HBA) for $\mathrm{CO}_{2}$ separation. Moreover, the selected DESs physical features were elaborated briefly. The result of this work demonstrated the newly solvent has low solubility of $\mathrm{CO}_{2}$ compared to other mentioned in literature [60]. Throughout the search directed in this work, it had been remarked that from the years 2009 to 2012 no analysis was performed for $\mathrm{CO}_{2}$ solubility in deep eutectics solvent. Although, an article was issued by Su et al. in 2009, which amid was to figure out the $\mathrm{CO}_{2}$ solubility with blend solvent of 1-aminomethanamide and choline chloride [61]. which indicated the highlight of intriguing research that is the utilising of amine in blending framework to get ready the DESs for $\mathrm{CO}_{2}$ capture. As far as we possibly know, the first previously revealed article treating $\mathrm{CO}_{2}$ dissolvability in Reline, by varying molar ratios 1: 1.5, $1: 2$ and 1: 2.5, also thermally reading from $313.15,323.15$ to 333.15 Kelvin and 30 Bar pressure was noted. It was indicated that the internal temperature and pressure of the system may affect $\mathrm{CO}_{2}$ dissolubility in the blends, as expending the pressure, expending the $\mathrm{CO}_{2}$ solubility. Furthermore, the dissolubility of $\mathrm{CO}_{2}$ in DES reduced as reducing the degree of hotness and coldness at all pressures, also noted the internal energy of the system was negative at all states. In addition, there is some survey which indicate the $\mathrm{CO}_{2}$ dissolubility in DESs which have caught attention dramatically within the three years.

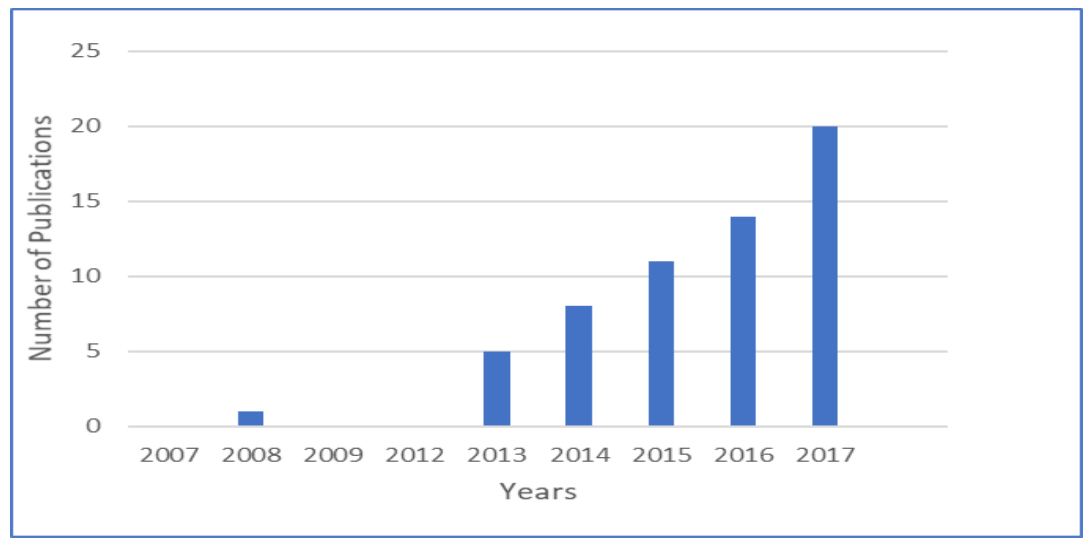

Figure 2. Numbering of articles exploring $\mathrm{CO}_{2}$ capturing untiring DESs in the period 2008 to 2017. 
From the Figure (2), it is evident that most articles have been published in DESs after the first published article in 2008 by Lu et al. which revealed the dissolubility of utilising DES in $\mathrm{CO}_{2}$ capturing to explore the variable of solubility. On the other hand, it is demonstrated that there was no publication over four years from 2009 to 2012. In contrast the given figure further represents drastically increased in the number of published articles over three years duration from 2013 to 2017. Deep eutectic solvents have caught great attention in almost every field, due to its flexible properties, for instance, biocompatibility, inexpensiveness, readily available, easy to prepare, ecological delicacy and recyclability. Besides, DESs have a low melting point, low viscosity and have an excellent capability for $\mathrm{CO}_{2}$ capturing. Due to these the favourable features of DESs, many researchers have been investigated various kind of DESs as showing exceptional performance as compared to conventional solvents. The investigated DESs are in specified Table (1).

Table 1. Dissolubility of $\mathrm{CO}_{2}$ in various Deep eutecticsolvents.

Variable parameters for $\mathrm{CO}_{2}$ dissolubility in different $\mathrm{DES}_{\mathrm{s}}$

Hydrogen bond accepters Hydrogen bond donors

\begin{tabular}{|c|c|c|c|c|c|c|}
\hline$\left(\mathrm{HBA}_{\mathrm{s}}\right)$ & $\left(\mathrm{HBD}_{\mathrm{s}}\right)$ & Molar Ratio & $T(\mathrm{k})$ & $P(\mathrm{MPa}$ & $\mathrm{mCO}_{2}$ & $\begin{array}{c}\text { Years / } \\
\text { References }\end{array}$ \\
\hline Choline chloride $(\mathrm{ChCl})$ & Monoethanolamine & $1: 6$ & 313.15 & $0-6$ & $0.3 \mathrm{~mol} / \mathrm{g}$ & $2020[62]$ \\
\hline $\mathrm{ChCl}$ & Diethanolamine & $1: 8$ & 313.15 & $0-6$ & 0.16 & \\
\hline \multirow[t]{2}{*}{$\mathrm{ChCl}$} & Methyl diethanolamine & $1: 10$ & 313.15 & $0-6$ & 0.02 & \\
\hline & Tetrabutyl Ammonium & $1: 4$ & 303.15 & 10.46 & $0.30-0.106$ & $2020[63]$ \\
\hline \multirow{3}{*}{ MEA } & Bromide & & & & & \\
\hline & $\begin{array}{c}\text { Benzyltriethyl } \\
\text { ammonium Chloride }\end{array}$ & $1: 4$ & 303.15 & 10.07 & $0.24-0.100$ & \\
\hline & Tetrabutyl Ammonium & $1: 4$ & & 09.93 & $0.22-0.071$ & \\
\hline \multirow[t]{2}{*}{ EAE } & Bromide & & 303.15 & & & \\
\hline & $\begin{array}{c}\text { Benzyltriethyl } \\
\text { ammonium Chloride }\end{array}$ & $1: 4$ & 303.15 & 10.19 & 0.24- 0.09 & \\
\hline $\mathrm{ChCl}$ & Diethanolamine & $5 w t \%-40 w t \%$ & 276.15 & 15 & 0.146 & 2020 [62] \\
\hline Choline Chloride & Lactic acid & $2: 1$ & 348.15 & 19.27 & $0.0248 \mathrm{~mol} / \mathrm{mol}$ & 2013 [64] \\
\hline
\end{tabular}




\begin{tabular}{|c|c|c|c|c|c|c|}
\hline $\begin{array}{c}\text { Benzyltriphenylphosphonium } \\
\text { chloride }\end{array}$ & Glycerol & $1: 12$ & 298.15 & 10 bars & 0.0511 & 2015 [35] \\
\hline $\begin{array}{l}\text { n-Butyltriphenylphosphoniu } \\
\text { m } \\
\text { bromide }\end{array}$ & Ethane-1,2-diol & $1: 12$ & 298.15 & 10 bars & 0.0503 & \\
\hline $\mathrm{ChCl}$ & Monoethylene amine & $1: 10$ & 313.15 & 1 bar & 0.35 & 2017 [54] \\
\hline $\mathrm{ChCl}$ & Diethylene amine & $1: 10$ & 313.15 & 1 bar & 0.18 & \\
\hline
\end{tabular}

Table 1. cont.

Variable parameters for $\mathrm{CO}_{2}$ dissolubility in different $\mathrm{DES}_{\mathrm{s}}$

Hydrogen bond accepters Hydrogen bond donors

\begin{tabular}{|c|c|c|c|c|c|c|}
\hline$\left(\mathrm{HBA}_{\mathrm{s}}\right)$ & $\left(\mathrm{HBD}_{\mathrm{s}}\right)$ & Molar Ratio & $T(\mathrm{k})$ & $P(\mathrm{MPa}$ & $\mathrm{mCO}_{2}$ & $\begin{array}{c}\text { Years / } \\
\text { References }\end{array}$ \\
\hline $\mathrm{ChCl}$ & Carbamide & 1.1 .5 & 332.15 & 0.5 & 0.6 & 2017 [55] \\
\hline $\mathrm{ChCl}$ & Carbamide & $1: 2.5$ & 332.15 & 0.5 & 0.3 & \\
\hline $\mathrm{ChCl}$ & Carbamide + water & $1: 2+(0.0185)$ & $308.2+$ & 4.376 & 0.169 & 2014 \\
\hline $\mathrm{ChCl}$ & Carbamide + water & $1: 2+(0.910)$ & 308.2 & 4.504 & 0.151 & \\
\hline $\mathrm{ChCl}$ & Carbamide + water & $1: 2+(1.83)$ & 308.2 & 4.499 & 0.143 & \\
\hline $\mathrm{ChCl}$ & Carbamide + water & $\begin{array}{c}\text { Reline }(0.00 \%) \text { in } \\
\text { water }\end{array}$ & 303 & $1 \mathrm{bar}$ & 5.2 & 2009 [61] \\
\hline $\mathrm{ChCl}$ & Carbamide $+\mathrm{H}_{2} \mathrm{O}$ & $\begin{array}{c}\text { Reline( } 86.2 \%) \text { in } \\
\text { water }\end{array}$ & 303 & 1 bar & 17 & \\
\hline $\mathrm{ChCl}$ & Carbamide $+\mathrm{H}_{2} \mathrm{O}$ & $\begin{array}{c}\text { Reline }(99.10 \%) \text { in } \\
\text { water }\end{array}$ & 303 & 1 bar & 27 & \\
\hline
\end{tabular}

These given tables exhibited the solubility of $\mathrm{CO}_{2}$ in many different DESs but most of DESs used as $\mathrm{CO}_{2}$ dissolubility are choline chloride and reline based and their solubility by increasing their amount of concentration. In addition, the following chemical species are investigated as DESs based for the first time in existing literature for carbon dioxide capture and storage. It also demonstrated that DES can be good alternative to ILs. 


\section{Conclusions}

This review article sums up the influential physiochemical properties of DESs and their application for CCS operations. DESs are a novel generation solvent just like the ILs, but with some varying properties. The most important segment of this paper, which is all about DESs preparation and chemical structures indicated the main factors that influence DESs. Although, the available literature on $\mathrm{CO}_{2}$ gas solubility is confined, the literature study shows better viability of $\mathrm{CO}_{2}$ solubility in DESs in comparison with the conventional solvents. On the other hand, significant outcomes have been discovered all around by several researchers, that DESs is known as a viable green solvent with good performance $\mathrm{CO}_{2}$ capture. The progress shown in Figure 2 is a good sign for the possibility of implementing DES for industrial practices involving contaminated $\mathrm{CO}_{2}$ control in near future. It is highly recommended for the researchers to focus more on DES and utilise the properties for greener applications.

\section{Acknowledgment}

The authors gratefully acknowledge Universiti Teknologi PETRONAS and MRA Grant GR\&T 015MD0-028 for providing the financial and technical support to complete the present work. Special thanks to those who contributed to this project.

\section{References}

[1] B. Li, Y. Duan, D. Luebke, and B. Morreale, "Advances in CO2 capture technology: A patent review," Appl. Energy, vol. 102, pp. 1439-1447, 2013, doi: 10.1016/j.apenergy.2012.09.009.

[2] C. Song, "Global challenges and strategies for control, conversion and utilization of CO2 for sustainable development involving energy, catalysis, adsorption and chemical processing,"

Catal. Today, vol. 115, no. 1-4, pp. 2-32, 2006, doi: 10.1016/j.cattod.2006.02.029.

[3] M. Shokrollahi Yancheshmeh, H. R. Radfarnia, and M. C. Iliuta, "High temperature CO2 sorbents and their application for hydrogen production by sorption enhanced steam reforming process," Chem. Eng. J., vol. 283, pp. 420-444, 2016, doi: 10.1016/j.cej.2015.06.060. [4] T. N. G. Borhani, A. Azarpour, V. Akbari, S. R. Wan Alwi, and Z. A. Manan, “CO2 capture with potassium carbonate solutions: A state-of-the-art review," Int. J. Greenh. Gas Control, vol. 41, pp. 142-162, 2015, doi: 10.1016/j.ijggc.2015.06.026.

[5] R. Sabouni, H. Kazemian, and S. Rohani, “Carbon dioxide capturing technologies: A review focusing on metal organic framework materials (MOFs)," Environ. Sci. Pollut. Res., vol. 21, no. 8, pp. 5427-5449, 2014, doi: 10.1007/s11356-013-2406-2.

[6] D. Kussainova and D. Shah, "Monoethanolamine based DESs for CO2 absorption: Insights from molecular dynamics simulations," Sep. Purif. Technol., vol. 231, no. August 2019, p. 115931, 2020, doi: 10.1016/j.seppur.2019.115931.

[7] M. K. Mondal, H. K. Balsora, and P. Varshney, "Progress and trends in CO2 capture/separation technologies: A review," Energy, vol. 46, no. 1, pp. 431-441, 2012, doi: 10.1016/j.energy.2012.08.006.

[8] H. Yang et al., "Progress in carbon dioxide separation and capture: A review," J. Environ. Sci., vol. 20, no. 1, pp. 14-27, 2008, doi: 10.1016/S1001-0742(08)60002-9.

[9] O. G. Brakstad et al., "Seawater biodegradation of alkanolamines used for CO 2-capture from 
natural gas," Int. J. Greenh. Gas Control, vol. 10, pp. 271-277, 2012, doi:

10.1016/j.ijggc.2012.06.016.

[10] A. Chremos, E. Forte, V. Papaioannou, A. Galindo, G. Jackson, and C. S. Adjiman,

"Modelling the phase and chemical equilibria of aqueous solutions of alkanolamines and carbon dioxide using the SAFT- $\gamma$ SW group contribution approach," Fluid Phase Equilib., vol. 407, pp. 280-297, 2016, doi: 10.1016/j.fluid.2015.07.052.

[11] C. Dinca, "Critical parametric study of circulating fluidized bed combustion with CO2 chemical absorption process using different aqueous alkanolamines," J. Clean. Prod., vol. 112, pp. 1136-1149, 2016, doi: 10.1016/j.jclepro.2015.06.051.

[12] F. Barzagli, F. Mani, and M. Peruzzini, "Efficient CO2 absorption and low temperature desorption with non-aqueous solvents based on 2-amino-2-methyl-1-propanol (AMP)," Int. J. Greenh. Gas Control, vol. 16, pp. 217-223, 2013, doi: 10.1016/j.ijggc.2013.03.026.

[13] G. Kim, W. Choi, C. H. Lee, and K. Lee, "Enhancement of dissolved inorganic carbon and carbon fixation by green alga Scenedesmus sp. in the presence of alkanolamine CO2 absorbents," Biochem. Eng. J., vol. 78, pp. 18-23, 2013, doi: 10.1016/j.bej.2013.02.010. [14] A. Shojaeian and A. Haghtalab, "Solubility and density of carbon dioxide in different aqueous alkanolamine solutions blended with 1-butyl-3-methylimidazolium acetate ionic liquid at high pressure," J. Mol. Liq., vol. 187, pp. 218-225, 2013, doi:

10.1016/j.molliq.2013.07.016.

[15] H. F. Hizaddin, M. K. Hadj-Kali, I. M. Alnashef, F. S. Mjalli, and M. A. Hashim, "Prediction of CO2 solubility in ionic liquids using the PSRK model," J. Supercrit. Fluids, vol. 100, pp. 184-193, 2015, doi: 10.1016/j.supflu.2015.02.009.

[16] F. Karadas, M. Atilhan, and S. Aparicio, "Review on the use of ionic liquids (ILs) as alternative fluids for CO 2 capture and natural gas sweetening," Energy and Fuels 11, pp. 5817-5828, 2010, doi: 10.1021/ef1011337

[17] M. Ramdin, T. W. De Loos, and T. J. H. Vlugt, "State-of-the-art of CO 2 capture with ionic liquids," Ind. Eng. Chem. Res., vol. 51, no. 24, pp. 8149-8177, 2012, doi: 10.1021/ie3003705.

[18] R. Biczak, B. Pawłowska, P. Bałczewski, and P. Rychter, "The role of the anion in the toxicity of imidazolium ionic liquids," J. Hazard. Mater., vol. 274, pp. 181-190, 2014, doi:

10.1016/j.jhazmat.2014.03.021.

[19] L. Chen, M. Sharifzadeh, N. Mac Dowell, T. Welton, N. Shah, and J. P. Hallett, “Inexpensive ionic liquids: [HSO4]--based solvent production at bulk scale," Green Chem., vol. 16, no. 6, pp. 3098-3106, 2014, doi: 10.1039/c4gc00016a.

[20] M. Hayyan, T. Aissaoui, M. A. Hashim, M. A. H. AlSaadi, and A. Hayyan, "Triethylene glycol based deep eutectic solvents and their physical properties," J. Taiwan Inst. Chem. Eng., vol. 50, pp. 24-30, 2015, doi: 10.1016/j.jtice.2015.03.001.

[21] G. García, M. Atilhan, and S. Aparicio, "A theoretical study on mitigation of CO2 through advanced deep eutectic solvents," Int. J. Greenh. Gas Control, vol. 39, pp. 62-73, 2015, doi: 10.1016/j.ijggc.2015.05.004.

[22] S. H. Wu, A. R. Caparanga, R. B. Leron, and M. H. Li, "Vapor pressure of aqueous choline chloride-based deep eutectic solvents (ethaline, glyceline, maline and reline) at 30-70 ${ }^{\circ} \mathrm{C}$," Thermochim. Acta, vol. 544, pp. 1-5, 2012, doi: 10.1016/j.tca.2012.05.031.

[23] Y. Dai, J. van Spronsen, G. J. Witkamp, R. Verpoorte, and Y. H. Choi, "Natural deep eutectic solvents as new potential media for green technology," Anal. Chim. Acta, vol. 766, pp. 61-68, 
2013, doi: 10.1016/j.aca.2012.12.019.

[24] V. A. Online et al., "A detailed study of cholinium chloride and levulinic acid deep eutectic solvent system for CO 2 capture via experimental and molecular," pp. 49-52, 2015, doi: 10.1039/С5СР03364K.

[25] M. A. Kareem, F. S. Mjalli, M. A. Hashim, and I. M. Alnashef, "Phosphonium-based ionic liquids analogues and their physical properties," J. Chem. Eng. Data, vol. 55, no. 11, pp. 4632-4637, 2010, doi: 10.1021/je100104v.

[26] A. Shishov, A. Bulatov, M. Locatelli, S. Carradori, and V. Andruch, "Application of deep eutectic solvents in analytical chemistry . A review," Microchem. J., vol. 135, pp. 33-38, 2017, doi: 10.1016/j.microc.2017.07.015.

[27] Q. Zhang, K. De Oliveira Vigier, S. Royer, and F. Jérôme, “Deep eutectic solvents: Syntheses, properties and applications," Chem. Soc. Rev., vol. 41, no. 21, pp. 7108-7146, 2012, doi:

$10.1039 /$ c2cs35178a.

[28] A. P. Abbott, G. Capper, D. L. Davies, R. K. Rasheed, and V. Tambyrajah, “Novel solvent properties of choline chloride/urea mixtures," Chem. Commun., no. 1, pp. 70-71, 2003, doi: $10.1039 / \mathrm{b} 210714 \mathrm{~g}$.

[29] C. Mukesh, D. Mondal, M. Sharma, and K. Prasad, "Choline chloride-thiourea, a deep eutectic solvent for the production of chitin nanofibers," Carbohydr. Polym., vol. 103, no. 1, pp. 466-471, 2014, doi: 10.1016/j.carbpol.2013.12.082.

Appl. Sci. 2020, 10, x FOR PEER REVIEW 12 of 14

[30] Q. Q. Xiong, J. P. Tu, X. Ge, X. L. Wang, and C. D. Gu, “One-step synthesis of hematite nanospindles from choline chloride/urea deep eutectic solvent with highly powerful storage versus lithium," J. Power Sources, vol. 274, pp. 1-7, 2015, doi: 10.1016/j.jpowsour.2014.10.020.

[31] L. Gu, W. Huang, S. Tang, S. Tian, and X. Zhang, "A novel deep eutectic solvent for biodiesel preparation using a homogeneous base catalyst," Chem. Eng. J., vol. 259, pp. 647-652, 2015, doi: 10.1016/j.cej.2014.08.026.

[32] A. Hayyan, M. A. Hashim, M. Hayyan, F. S. Mjalli, and I. M. Alnashef, "A new processing route for cleaner production of biodiesel fuel using a choline chloride based deep eutectic solvent," J. Clean. Prod., vol. 65, pp. 246-251, 2014, doi: 10.1016/j.jclepro.2013.08.031.

[33] E. Ali et al., "Solubility of CO2 in deep eutectic solvents: Experiments and modelling using the Peng-Robinson equation of state," Chem. Eng. Res. Des., vol. 92, no. 10, pp. 1898-1906, 2014, doi: 10.1016/j.cherd.2014.02.004.

[34] J. G. Lu et al., "Property of diethanolamine glycinate ionic liquid and its performance for CO2 capture," J. Mol. Liq., vol. 211, pp. 1-6, 2015, doi: 10.1016/j.molliq.2015.06.059.

[35] K. K. Kow and K. Sirat, “Novel manganese(II)-based deep eutectic solvents: Synthesis and physical properties analysis," Chinese Chem. Lett., vol. 26, no. 10, pp. 1311-1314, 2015, doi: 10.1016/j.cclet.2015.05.049.

[36] M. Hayyan et al., "Are deep eutectic solvents benign or toxic?," Chemosphere, vol. 90, no. 7, pp. 2193-2195, 2013, doi: 10.1016/j.chemosphere.2012.11.004.

[37] Z. L. Huang, B. P. Wu, Q. Wen, T. X. Yang, and Z. Yang, “Deep eutectic solvents can be viable enzyme activators and stabilizers," J. Chem. Technol. Biotechnol., vol. 89, no. 12, pp. 1975-1981, 2014, doi: 10.1002/jctb.4285.

[38] T. Aissaoui, I. M. AlNashef, and Y. Benguerba, "Dehydration of natural gas using choline 3 chloride based deep eutectic solvents: COSMO-RS prediction," J. Nat. Gas Sci. Eng., vol. 30, 
pp. 571-577, 2016, doi: 10.1016/j.jngse.2016.02.007.

[39] S. L. Perkins, P. Painter, and C. M. Colina, "Molecular dynamic simulations and vibrational analysis of an ionic liquid analogue," J. Phys. Chem. B, vol. 117, no. 35, pp. 10250-10260, 2013, doi: 10.1021/jp404619x.

[40] J. García-Álvarez, “Deep Eutectic Mixtures: Promising Sustainable Solvents for Metal-Catalysed and Metal-Mediated Organic Reactions," Eur. J. Inorg. Chem., vol. 2015, no. 31, pp. 5147-5157, 2015, doi: 10.1002/ejic.201500892.

[41] X. Li and K. H. Row, "Development of deep eutectic solvents applied in extraction and separation," J. Sep. Sci., vol. 39, no. 18, pp. 3505-3520, 2016, doi: 10.1002/jssc.201600633.

[42] T. Aissaoui and I. M. AlNashef, “COSMO-RS Prediction for Choline Chloride-Urea Based depe eutectic solvent-Chemical structure and application as agent for natural gas dehydration," Int. J. Chem. Mol. Eng., vol. 11, no. 1, p. 54007, 2017.

[43] A. P. Abbott, J. C. Barron, K. S. Ryder, and D. Wilson, "Eutectic-based ionic liquids with metal-containing anions and cations," Chem. - A Eur. J., vol. 13, no. 22, pp. 6495-6501, 2007, doi: 10.1002/chem.200601738.

[44] A. P. Abbott, R. C. Harris, and K. S. Ryder, "Application of hole theory to define ionic liquids by their transport properties," J. Phys. Chem. B, vol. 111, no. 18, pp. 4910-4913, 2007, doi: 10.1021/jp0671998.

[45] L. Liu, C. Zhao, J. Xu, and Y. Li, “Integrated CO2 capture and photocatalytic conversion by a Appl. Sci. 2020, 10, x FOR PEER REVIEW 13 of 14

hybrid adsorbent/photocatalyst material," Appl. Catal. B Environ., vol. 179, pp. 489-499, 2015, doi: 10.1016/j.apcatb.2015.06.006.

[46] M. Pishahang, Y. Larring, M. McCann, and R. Bredesen, “Ca0.9Mn0.5Ti0.5O3-§: A suitable oxygen carrier material for fixed-bed chemical looping combustion under syngas conditions," Ind. Eng. Chem. Res., vol. 53, no. 26, pp. 10549-10556, 2014, doi:

10.1021/ie500928m.

[47] P. Luis, T. Van Gerven, and B. Van Der Bruggen, "Recent developments in membrane-based technologies for CO 2 capture," Prog. Energy Combust. Sci., vol. 38, no. 3, pp. 419-448, 2012, doi: 10.1016/j.pecs.2012.01.004.

[48] J. D. Figueroa, T. Fout, S. Plasynski, H. Mcllvried, and R. D. Srivastava, "Advances in CO2 capture technology-The U.S. Department of Energy's Carbon Sequestration Program," Int. J. Greenh. Gas Control, vol. 2, no. 1, pp. 9-20, 2008, doi: 10.1016/S1750-5836(07)00094-1.

[49] Z. Niu, Y. Guo, Q. Zeng, and W. Lin, "Experimental Studies and Rate-Based Process Simulations of CO 2 Absorption with Aqueous Ammonia Solutions," 2012.

[50] T. Aissaoui, I. M. Alnashef, U. A. Qureshi, and Y. Benguerba, "Potential applications of deep eutectic solvents in natural gas sweetening for CO 2 capture," 2017, doi:

10.1515/revce-2016-0013.

[51] J. Lu et al., "CO 2 capture by membrane absorption coupling process : Application of ionic liquids," Appl. Energy, vol. 115, pp. 573-581, 2014, doi: 10.1016/j.apenergy.2013.10.045.

[52] J. D. Mota-morales, R. J. Sánchez-leija, A. Carranza, J. A. Pojman, and G. Luna-bárcenas, "Progress in Polymer Science Free-radical polymerizations of and in deep eutectic solvents: Green synthesis of functional materials," Prog. Polym. Sci., vol. 78, pp. 139-153, 2018, doi: 10.1016/j.progpolymsci.2017.09.005.

[53] S. Sarmad, Y. Xie, J. P. Mikkola, and X. Ji, "Screening of deep eutectic solvents (DESs) as green 
CO2 sorbents: from solubility to viscosity," New J. Chem., vol. 41, no. 1, pp. 290-301, 2016, doi: 10.1039/c6nj03140d.

[54] I. Adeyemi, M. R. M. Abu-zahra, and I. Alnashef, "Experimental Study of the Solubility of CO 2 in Novel Amine Based Deep Eutectic Solvents," Energy Procedia, vol. 105, pp. 1394-1400, 2017, doi: 10.1016/j.egypro.2017.03.519.

[55] A. Kamgar, S. Mohsenpour, and F. Esmaeilzadeh, "Solubility prediction of CO2, CH4, H2, $\mathrm{CO}$ and N2 in Choline Chloride/Urea as a eutectic solvent using NRTL and COSMO-RS models," J. Mol. Liq., 2017, doi: 10.1016/j.molliq.2017.09.101.

[56] J. C. Thermodynamics, D. Deng, Y. Jiang, X. Liu, Z. Zhang, and N. Ai, "Investigation of solubilities of carbon dioxide in five levulinic acid-based deep eutectic solvents and their thermodynamic properties," J. Chem. Thermodyn., vol. 103, pp. 212-217, 2016, doi: 10.1016/j.jct.2016.08.015.

[57] Y. Chen, N. Ai, G. Li, H. Shan, Y. Cui, and D. Deng, "Solubilities of carbon dioxide in eutectic mixtures of choline chloride and dihydric alcohols," J. Chem. Eng. Data, vol. 59, no. 4, pp. 1247-1253, 2014, doi: 10.1021/je400884v.

[58] N. Ra, N. J. Nicholas, Y. Wu, K. A. Mumford, S. E. Kentish, and W. Stevens, “Experiments and Thermodynamic Modeling of the Solubility of Carbon Dioxide in Three Di ff erent Deep Eutectic Solvents (DESs)," 2015, doi: 10.1021/acs.jced.5b00492.

[59] Y. Xie, H. Dong, S. Zhang, X. Lu, and X. Ji, "Effect of water on the density, viscosity, and CO2 Appl. Sci. 2020, 10, x FOR PEER REVIEW 14 of 14

solubility in choline chloride/urea," J. Chem. Eng. Data, vol. 59, no. 11, pp. 3344-3352, 2014, doi: 10.1021/je500320c.

[60] M. Francisco, A. van den Bruinhorst, L. F. Zubeir, C. J. Peters, and M. C. Kroon, “A new low transition temperature mixture (LTTM) formed by choline chloride+lactic acid:

Characterization as solvent for CO2 capture," Fluid Phase Equilib., vol. 340, pp. 77-84, 2013, doi: 10.1016/j.fluid.2012.12.001.

[61] W. C. Su, D. S. H. Wong, and M. H. Li, "Effect of water on solubility of carbon dioxide in (aminomethanamide + 2-hydroxy-N,N,N-trimethylethanaminium chloride)," J. Chem. Eng. Data, vol. 54, no. 6, pp. 1951-1955, 2009, doi: 10.1021/je900078k.

[62] S. Maneshdavi, S. Mohsen, and S. Sayyahi, "Solubility of CO 2 in Aqueous Solutions of Diethanolamine ( DEA ) and Choline Chloride," vol. 54, no. 1, pp. 57-72, 2020, doi: 10.22059/jchpe.2020.284101.1289.

[63] M. B. Haider and R. Kumar, "Solubility of CO 2 and $\mathrm{CH} 4$ in sterically hindered amine-based deep eutectic solvents," Sep. Purif. Technol., vol. 248, no. April, p. 117055, 2020, doi:

10.1016/j.seppur.2020.117055.

[64] M. Francisco, A. Van Den Bruinhorst, L. F. Zubeir, C. J. Peters, and M. C. Kroon, "Fluid Phase Equilibria A new low transition temperature mixture ( LTTM ) formed by choline chloride + lactic acid : Characterization as solvent for CO 2 capture," Fluid Phase Equilib., vol. 340, pp. 77-84, 2013, doi: 10.1016/j.fluid.2012.12.001. 